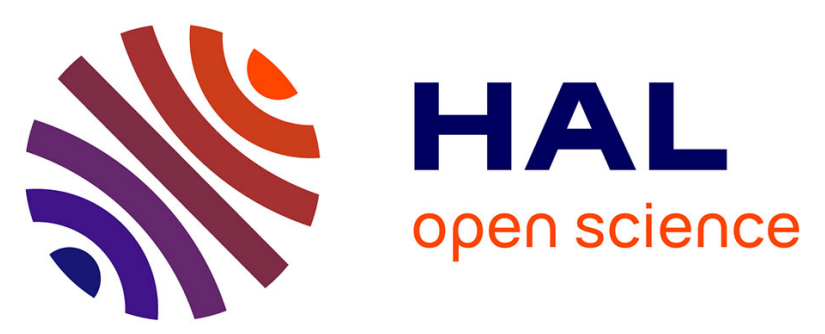

\title{
Improving a hardwood flooring cutting system through simulation and optimization
}

Jean Wery, Philippe Marier, Jonathan Gaudreault, Corinne Chabot, André

Thomas

\section{- To cite this version:}

Jean Wery, Philippe Marier, Jonathan Gaudreault, Corinne Chabot, André Thomas. Improving a hardwood flooring cutting system through simulation and optimization. 2015 Winter Simulation Conference, WSC'15, Dec 2015, Huntington Beach, California, United States. 10.1109/WSC.2015.7408330 . hal-01281212

\section{HAL Id: hal-01281212 \\ https://hal.science/hal-01281212}

Submitted on 1 Mar 2016

HAL is a multi-disciplinary open access archive for the deposit and dissemination of scientific research documents, whether they are published or not. The documents may come from teaching and research institutions in France or abroad, or from public or private research centers.
L'archive ouverte pluridisciplinaire HAL, est destinée au dépôt et à la diffusion de documents scientifiques de niveau recherche, publiés ou non, émanant des établissements d'enseignement et de recherche français ou étrangers, des laboratoires publics ou privés. 


\title{
IMPROVING A HARDWOOD FLOORING CUTTING SYSTEM THROUGH SIMULATION AND OPTIMIZATION
}

\author{
Jean Wery \\ Philippe Marier \\ Jonathan Gaudreault \\ FORAC Research Consortium \\ Université Laval \\ 1065, av. de la Médecine \\ Quebec (QC), G1V 0Q6, CANADA \\ Corinne Chabot \\ Centre de Recherche Industrielle du Québec \\ (CRIQ) \\ 333, rue Franquet \\ Quebec (QC), G1P 4C7, CANADA
}

\author{
André Thomas \\ Centre de Recherche en Automatique de Nancy (CRAN) \\ Université de Lorraine \\ 27, rue Philippe Séguin \\ Epinal, 88 000, FRANCE
}

\begin{abstract}
Hardwood flooring mills transform rough wood into several boards of smaller dimensions. For each piece of raw material, the system tries to select the cutting pattern that will generate the greatest value, taking into account the characteristics of the raw material. However, it is often necessary to choose less profitable cutting patterns in order to respect market constraints. This reduces production value, but it is the price to pay in order to satisfy the market. We propose an approach to improve production value. We first use simulation on a training set of virtual boards in order to generate a database associating cutting patterns to expected production value. Then, we use an optimization model to generate a production schedule maximizing the expected production value while satisfying production constraints. The approach is evaluated using industrial data. This allows recovering approximately $30 \%$ of the value lost when using the original system.
\end{abstract}

\section{INTRODUCTION}

Manufacturing hardwood flooring is a constant challenge. The process involves co-production (each piece of rough wood is cut to produce many pieces at the same time) and many different cutting patterns can be used. As each piece of raw material shows different physical characteristics (wood is a natural product) we need to carefully select the cutting pattern that will be applied to each piece of raw material in order to maximize production value.

In industrial practice, these decisions are made in real time, one piece of raw material after another. However, other production constraints force the system to dynamically deactivate some cutting patterns/finished products when it detects that the quantities of a given product are too high or too low. Therefore, current production systems used by the industry are said to be reactive (they deactivate some cutting patterns when they detect that a constraint has been violated) instead of being proactive. 
In this study, we used simulation and an optimization model to evaluate a proactive approach. Results show it would lead to considerable benefits for the industry.

The remainder of this paper is organized as follows. Section 2 introduces some basic concepts concerning the hardwood flooring industry as well as the use of simulation and optimization in the forestproducts sector. Section 3 introduces our proactive approach, the methodology and the optimization model developed to support it. Finally, we apply the methodology to a case study in order to show the relevance of our approach (Section 4).

\section{PRELIMINARY CONCEPTS}

\subsection{Hardwood Flooring Transformation Process}

Hardwood flooring mill transforms each rough-wood board (raw material) into several boards (finished products) of smaller dimensions with variable grade and length (it is a co-production process with divergent product flow). The process is detailed in Figure 1. For a given production shift, a batch of boards (1) showing similar characteristics (e.g. specie, thickness) is processed. The bundle is unstacked (2) and each individual board (3) is scanned using cameras and captors. Data is analyzed (4) in order to get a parametrical description (quality, measurement, position of the defects, etc...) of each board (5). Finally, the "optimizer" selects (6) the best cutting patterns (8) among a set of available standard cutting patterns (7) provided by the mill. The board is then cut accordingly (9). Similar products are packed (10) together.

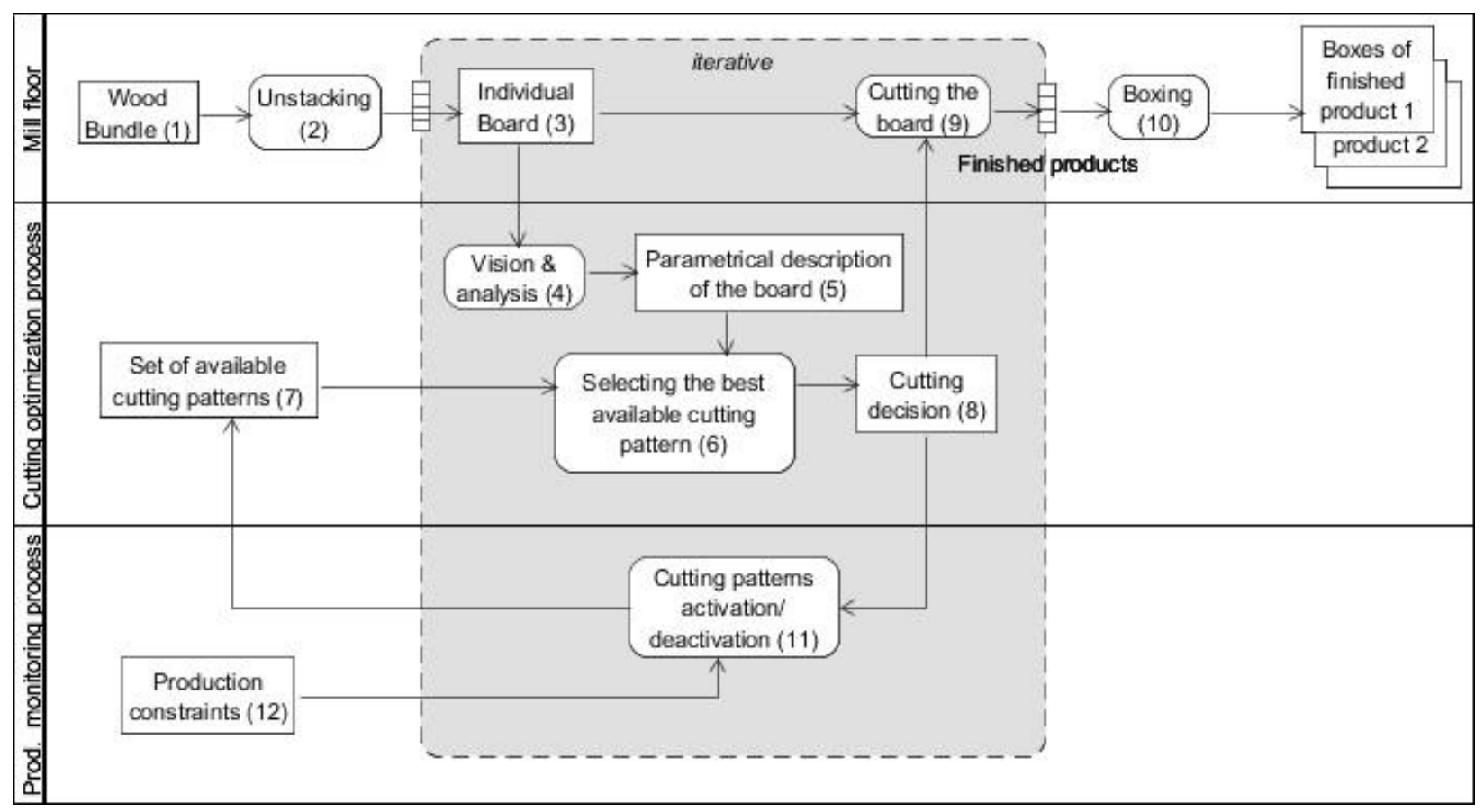

Figure 1: Current hardwood cutting process. 
The system always selects the cutting pattern that will generate the greatest value, taking into account the real dimensions of the boards as well as defects, their natures, their positions, their dimensions or even color seen on the board. However, in the hardwood flooring industry, companies must respect different sets of constraints. As a simple example, each box must contain boards showing an appropriate mix of lengths. Similar constraints exist for color variations and other characteristics, etc. Optimizing only the value of each individual board would not satisfy market and packaging constraints.

Consequently, the "optimizer" is sometimes obliged to choose less profitable cutting patterns in order to respect production constraints (12) (e.g. if until now X\% of the boards are "long", then cutting patterns containing this product need to be deactivated for a while). Therefore, the set of available cutting patterns is dynamically and continuously modified (11) according to recent decisions statistics (8).

\subsection{Drawbacks}

Adjusting the production in real time each time a constraint has been violated has a big influence on value/profits. One explanation is that the system is totally blind about what to expect next.

Here is a simplified case to picture this. Let's suppose there are three different finished products that can be produced: A (highly profitable), B (profitable) and $\mathbf{C}$ (less profitable). Cutting patterns are defined such that for one given input board, we can produce either "A and C", "B and C" or "only $\mathbf{C}$ ". We also have some market constraints: there should be no more than $20 \%$ of $\mathbf{A}$ and $50 \%$ of B in the overall production. Thus, the system starts the production trying to produce only "A and C" till the first constraint is violated (no more than $20 \%$ of product A). As a consequence, the system will then start producing "B and $\mathbf{C}$ " till the next constraint is violated (no more than $50 \%$ of product $\mathbf{B}$ ). The system is then obliged to produce "only C" till A or B is no longer constrained. However, knowing how the raw material looks, it would have been much more profitable to produce a mix of "A and C" and "B and C" from the beginning, rather than sometimes to have to produce "only C".

To overcome this, we will propose in Section 3 a proactive approach that exploits simulation in order to forecast production, thus allowing optimizing the use of the different cutting patterns in advance. Other authors have used simulation and optimization for other decision problems in the forest sector. The next section provides a quick overview of some of these contributions.

\subsection{Combining Simulation and Optimization in the Forest Products Industry}

In the forest products industry, simulation is often used to get information which is then used to feed decision-making models. Sinclair and Erasmus (1992) proposed an approach based on simulation and linear programming for operations planning in sawmills. They use simulation (SIMSAW software) to get data about different trees/logs cutting patterns. Using this data as input in their tool helps to realize operational planning.

For a South African forest products supply chain, Wessels et al. (2006) developed a package called "Sawmill Production Planning System". It combines linear and mixed integer programming techniques in order to make operational, tactical or strategic planning of forest harvesting and sawmilling operations using SIMSAW simulation results.

Recently, Wery et al. (2014) proposed a decision-making framework for tactical planning of a sawmill. This framework is used to decide if a customer demand for a new product should be satisfied and if so, at what price. When introducing a new product to the normal mix of products, coproduction and divergent flow makes it really hard to know what the new proportion of each product should be in the new mix of products. The framework uses simulation (Optitek log breakdown simulator) to create data about the overall production when the new product is introduced. This data feeds a tactical planning optimization model which gives the mix of products that should be produced at each period. 
However, these works concern the log breakdown decision problem (transforming trees into rough pieces of wood) whereas in our study we are interested in secondary transformation (transforming each rough piece of wood into many boards that can be used for flooring).

Simulation is also used to compare several planning approaches. In Feng, D'Amours, and Beauregard (2010) simulation is carried on to compare different planning approaches for an Oriented Strand Board (OSB) company. Different mixed integer programs (MIP) are used to generate the plans and they are compared using simulation.

Simulation can also be used to verify if a plan given by an optimization model is adequate or not. Jerbi et al. (2012) first make a tactical plan using an optimization model for a complex lumber supply chain. They then use simulation to verify the impacts of the tactical planning at the operational level. Marques et al. (2013) investigate the potential of combining optimization techniques with a discrete event simulator in order to realize the operational planning of forest harvesting and of raw material sawmill supplies. They generate optimized plans (scenarios) that are then simulated with a discrete event simulator in order to evaluate the dynamic behaviors of planned operations. They use performance indicators to compare scenarios.

Other authors like Todoroki and Rönnqvist (1999) or Wessels (2009) use optimization combined with simulation in the forest products industry. As an example, (Todoroki and Rönnqvist 2002) use a simulation model with dynamic programming in order to choose, among a few strategies, the best one that will satisfy a certain demand with as little raw material as possible in order to limit overproduction of some less needed/profitable finished products.

Combining multi-agent simulation with optimization methods in order to plan production has been tried in the forest products industry as well (Frayret et al. 2007, Santa-Eulalia, D'Amours, and Frayret 2012, Gaudreault et al. 2010).

Finally, others have used simulation results to train a neural network and use it afterward for decision making (e.g. Alifantis and Robinson 2001). In the approach proposed in the next section, simulation results are used to feed an optimization model that generates a production schedule. This is a classical approach to integrate simulation and optimization (see, for example, Liu and Takakuwa 2009).

\section{PROPOSED APPROACH BASED ON SIMULATION AND OPTIMIZATION}

In this section, we propose the use of simulation and an optimization model to develop a proactive approach for hardwood cutting decision-making. Simulating the cutting decision-making process by using the real system "offline" (this was made easy as the manufacturer of the equipment - CRIQ, http://www.criq.qc.ca/en/ - gave us access to the source code of their machine), we train our system in order to be able to foresee the impact of deactivating/activating cutting patterns. With this information in hand, we then establish a production schedule using a linear optimization model we developed that is expected to process future boards in a manner that will maximize production value while satisfying production constraints.

\subsection{Description of the Proposed Approach}

Figure 2 describes the simulation/training process. We assume we dispose of a database of board images (17) previously processed within the real production system. Then, while offline, the system is used to process the boards from the database (the system has no idea it is not processing real boards). Then, we process all the boards another time, this time deactivating production constraints (i.e. allowing all cutting patterns at any time). This allows measuring the value that is lost when one needs to satisfy production constraints. Furthermore, we can process the database again and again, each time allowing the system to use a different set of cutting patterns. This allows us to measure the impact of deactivating some specific products (that is, the expected production to be obtained when a given set of cutting patterns is available). These expected productions are recorded into a database (13). 
Wery, Marier, Gaudreault, Chabot, and Thomas

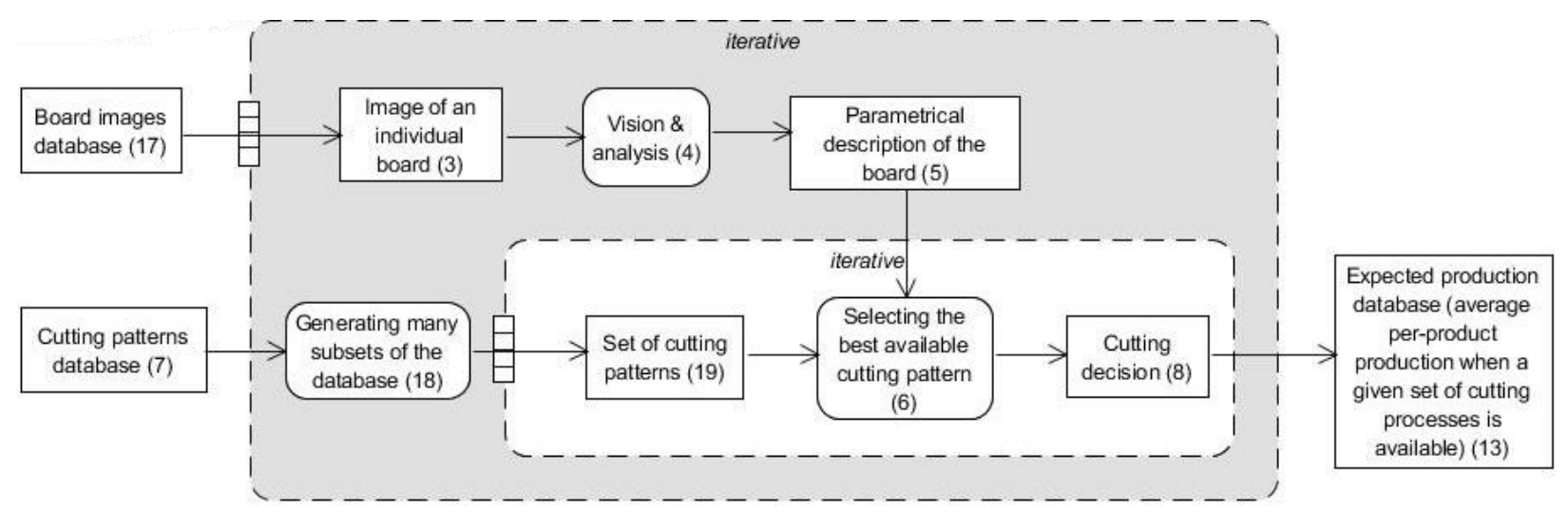

Figure 2: Using the system offline to create an expected production database.

With this information learned from the training database, we then try to establish a production schedule that is expected to process new boards (boards in a testing database) in a manner that will maximize production value while satisfying production constraints. This production schedule will specify the percentage of production time during which each set of cutting patterns should be activated.

Figure 3 illustrates this process. Solving a linear optimization problem (14), we can make a production schedule (15) which maximizes the expected production value according to the expected production (13) and production constraints (12). The production schedule (15) considers the production shift as separated in time slots. For each time slot, the schedule specifies the set of cutting patterns (7) that should be activated (16). If the production constraints database (12) is empty, the generated schedule will contain only one time slot for which all cutting patterns are activated at all times. If some production constraints need to be satisfied (actually, that is always the case) the schedule specifies how much time we should produce with all cutting patterns activated, as the following cutting patterns activations/deactivations temporal sequence.

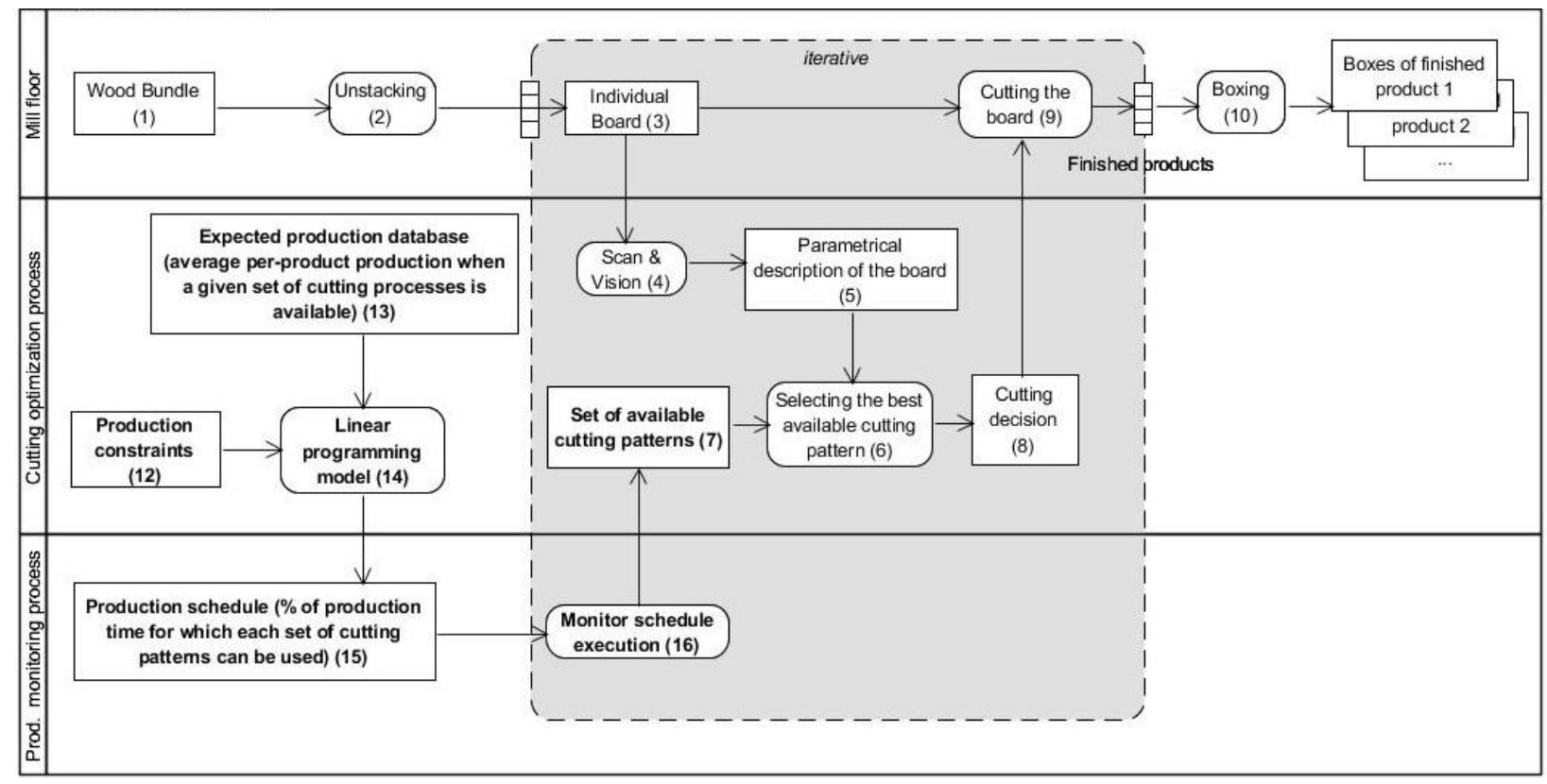

Figure 3: Executing the production schedule established using information learned during the training/simulation phase. 


\subsection{Optimization Model}

The model (14) used to generate the schedule is presented in this section.

\section{Sets:}

A Set of available cutting patterns $a$

$P_{c} \quad$ Set of products $p$ to which constraint $c$ apply

$P_{c}^{\text {base }} \quad$ Set of products $p$ used as a base for the computation of proportion in constraint $\mathrm{c}$

$C^{\text {unit }} \quad$ Set of constraints $c$ which are based on number of produced units

$C^{\text {length }}$ Set of constraints $c$ which are based on length of produced units

$C^{\% \text { unit }}$ Set of constraints $c$ which are based on proportion (in units) of production

$C^{\% \text { length }}$ Set of constraints $c$ which are based on proportion (in length) of production

\section{Parameters:}

$n \quad$ Number of boards available as raw material input

$l_{p} \quad$ Length of product $p$

$v_{p} \quad$ Price of product $p$

$g_{c}^{\min } \quad$ Minimal value for constraint $c$

$g_{c}^{\max } \quad$ Maximal value for constraint $c$

$q_{p, a} \quad$ Quantity of product $p$ produced when applying cutting pattern $a$ to one board of raw material

\section{Variables:}

$E_{a} \quad$ Number of times cutting pattern $a$ is used

\section{Objective function:}

$$
\text { Maximize } \sum_{a \in A} \sum_{p \in P} E_{a} q_{p, a} v_{p}
$$

\section{Constraints:}

Constraint on raw material availability:

$$
\sum_{a \in A} E_{a} \leq n
$$

Constraint on the produced quantities if the constraint type is based on number of produced units:

$$
g_{c}^{\min } \leq \sum_{a \in A} \sum_{p \in P_{c}} E_{a} q_{p, a} \leq g_{c}^{\max } \quad \forall c \in C^{\text {unit }}
$$


Constraint on the produced length if the constraint type is based on length produced:

$$
g_{c}^{\min } \leq \sum_{a \in A} \sum_{p \in P_{c}} E_{a} q_{p, a} l_{p} \leq g_{c}^{\max } \quad \forall c \in C^{\text {length }}
$$

Constraint on the produced quantities if the constraint type is based on proportion of produced units:

$$
g_{c}^{\min }\left(\sum_{a \in A} \sum_{p \in P_{c}^{b \text { ase }}} E_{a} q_{p, a}\right) \leq \sum_{a \in A} \sum_{p \in P_{c}} E_{a} q_{p, a} \leq g_{c}^{\max }\left(\sum_{a \in A} \sum_{p \in P_{c}^{\text {base }}} E_{a} q_{p, a}\right) \quad \forall c \in C^{\% \text { unit }}
$$

Constraint on the produced length if the constraint type is based on proportion of length produced:

$$
g_{c}^{\min }\left(\sum_{a \in A} \sum_{p \in P_{c}^{\text {base }}} E_{a} q_{p, a} l_{p}\right) \leq \sum_{a \in A} \sum_{p \in P_{c}} E_{a} q_{p, a} l_{p} \leq g_{c}^{\max }\left(\sum_{a \in A} \sum_{p \in P_{c}^{\text {base }}} E_{a} q_{p, a} l_{p}\right) \quad \forall c \in C^{\% \text { length }}
$$

\section{EXPERIMENTS}

We had access to a database containing 389 boards. We divided the database into two sets: a training set (1/3 of the boards) and a testing set (2/3 of the boards). The training set was used to feed our simulation setup described in Section 3 and Figure 2.

Each board of the training set was processed using each of the 39 different sets of cutting patterns we were provided with. This allowed us to generate the expected production database (see 13 on Figure 2).

We used this database to feed the mathematical programming model. We ran the model using Cplex in order to generate a schedule that was expected to meet production constraints of the company while maximizing the expected production value. We then simulated the execution of this schedule (see Figure 3 ). Boards from the testing set are used as raw material by the system which activates/deactivates cutting patterns according to the schedule.

We performed 10 different replications, each time testing the approaches using different training and testing sets of boards. Table 1 presents the results. All numerical results are scaled to present yearly results (supposing an average mill having an annual capacity of 60 million linear feet).

In order to provide a base case, we also processed the boards from each test set using the original reactive system. We can see in Table 1 that our approach increases value by $\$ 116805 \pm 82213$ (95\% confidence interval) in comparison with the base case (the design of our case study conforms with the criteria of Common Random Numbers).

We also processed the boards of each testing set in a setup where all the cutting patterns were always available (i.e. without having to respect production constraints). Thus, we were able to establish that meeting production costs $\$ 235630 \pm 54497$ per year (compared to the base case). This puts in perspective the performance of our proposed approach: it allows capturing around $32 \%$ of the maximum theoretical gain (Improvement / [Maximum theoretical gain - generated value of original reactive system]).

The relative gain (Improvement/Original system) can seem to be modest $(0,3 \%)$ but one needs to consider that profit margin in this industry may be quite small (less than $4 \%$ ), so achieving such an improvement without investment in new machines or reorganization of the plant is a significant improvement. 
Wery, Marier, Gaudreault, Chabot, and Thomas

Table 1: Results of the experiments.

\begin{tabular}{|c|c|c|c|c|c|}
\hline \multirow{3}{*}{ Dataset \# } & \multirow{3}{*}{$\begin{array}{c}\text { Not } \\
\text { mandatory to } \\
\text { meet } \\
\text { production } \\
\text { constraints, } \\
\text { generated } \\
\text { value } \\
\text { (\$ / year) }\end{array}$} & \multicolumn{4}{|c|}{ Mandatory to meeting production constraints } \\
\hline & & \multirow{2}{*}{$\begin{array}{l}\text { Original } \\
\text { reactive } \\
\text { system, } \\
\text { generated } \\
\text { value } \\
\text { (\$ / year) }\end{array}$} & \multicolumn{3}{|c|}{ Proposed approach } \\
\hline & & & $\begin{array}{l}\text { Generated } \\
\text { value } \\
\text { (\$/ year) }\end{array}$ & $\begin{array}{c}\text { Improvement } \\
\text { (\$ / year) }\end{array}$ & $\begin{array}{l}\text { Percentage } \\
\text { of } \\
\text { maximum } \\
\text { theoretical } \\
\text { gain } \\
\text { captured }\end{array}$ \\
\hline 1 & 40622620 & 40293681 & 40524459 & 230777 & $70 \%$ \\
\hline 2 & 40179358 & 39967074 & 40064673 & 97599 & $46 \%$ \\
\hline 3 & 41084440 & 40868634 & 40984682 & 116048 & $54 \%$ \\
\hline 4 & 40114124 & 39922665 & 40080639 & 157974 & $83 \%$ \\
\hline 5 & 41332189 & 41107996 & 41259215 & 151220 & $67 \%$ \\
\hline 6 & 40887980 & 40569717 & 40753353 & 183635 & $58 \%$ \\
\hline 7 & 41087800 & 40858004 & 40967532 & 109528 & $48 \%$ \\
\hline 8 & 41390447 & 41321092 & 41197421 & -123670 & $-178 \%$ \\
\hline 9 & 40098913 & 39788523 & 40052801 & 264279 & $85 \%$ \\
\hline 10 & 41114095 & 40858276 & 40838934 & -19342 & $-8 \%$ \\
\hline Average & 40791197 & 40555566 & 40672371 & 116805 & $32 \%$ \\
\hline Half width & 360041 & 382740 & 334192 & 82213 & \\
\hline
\end{tabular}

When we looked at the production schedule generated by the mathematical model, we noted that the expected values (anticipated by the mathematical model) are quite similar to the results obtained when executing the schedule (a difference of more or less 3\% on average). This leads us to believe that the size of our training set is sufficient to anticipate what the production will be with another set of boards (the test sets). However, for two datasets (\#8 and \#10), the value generated by the original reactive system was better than for the proposed approach. This is explained by the fact that, for these replications, the original system applied to the test sets some cutting patterns that were not available to us when we processed the training set (we trained using only 39 sets of cutting patterns). Therefore, we believe that training with more than 39 sets of cutting patterns (e.g. by extracting cutting patterns from historical data of the company) could improve the results.

Finally, although experimenting with the 389-board database allowed reaching significant improvements, the extrapolation to estimate an annual value should be interpreted carefully. We cannot be sure those 389 boards are really representative of the real raw material supply of the company. An evaluation of the system with a larger database would be needed. 
Wery, Marier, Gaudreault, Chabot, and Thomas

\section{CONCLUSION AND FUTURE WORK}

Cutting decisions for processes involving co-production are almost always done in real time, one piece of raw material after another. Some cutting patterns need to be activated/deactivated in real time to meet market/production constraints. This reduces production value, but it is the price the industry is willing to pay in order to satisfy market/production constraints.

Our case study showed that making use of simulation to gain a better knowledge of the raw material/cutting pattern production yield, and using that information in production scheduling may lead to an improvement (in produced value) in the order of $\$ 116805 \pm 82213$ /year for an average hardwood flooring factory. This represents approximately $32 \%$ of maximum theoretical gain.

In order to further improve the performance of our scheduler, we would like to increase the number of cutting patterns considered in the training phase. However, the number of such potential sets of cutting patterns is very large and it is numerically impossible to consider them all. Our future work will provide a methodology to find the sets of cutting patterns that should best meet the production constraints without having to simulate all of the possible sets.

Other experiments with larger board databases will be conducted as well.

\section{ACKNOWLEDGMENTS}

The authors would like to acknowledge the financial support of the Natural Sciences and Engineering Research Council of Canada (NSERC).

\section{REFERENCES}

Alifantis, T., and S. Robinson. 2001. "Using Simulation and Neural Networks to Develop a Scheduling Advisor". In Proceedings of the the 2001 Winter Simulation Conference, edited by J. S. Smith B. A. Peters, D. J. Medeiros, and M. W. Rohrer, 954-958. Piscataway, New Jersey: Institute of Electrical and Electronics Engineers, Inc.

Feng, Y., S. D’Amours, and R. Beauregard. 2010. "Simulation and Performance Evaluation of Partially and Fully Integrated Sales and Operations Planning." International Journal of Production Research 48 (19):5859-5883.

Frayret, J.-M., S. D’Amours, A. Rousseau, S. Harvey, and J. Gaudreault. 2007. "Agent-Based SupplyChain Planning in the Forest Products Industry." International Journal of Flexible Manufacturing Systems 19 (4):358-391.

Gaudreault, J., P. Forget, J.-M. Frayret, A. Rousseau, S. Lemieux, and S. D'Amours. 2010. "Distributed Operations Planning in the Softwood Lumber Supply Chain: Models and Coordination." International Journal of Industrial Engineering : Theory Applications and Practice 17 (3):168-189.

Jerbi, W., J. Gaudreault, S. D'Amours, M. Nourelfath, S. Lemieux, P. Marier, and M. Bouchard. 2012. "Optimization/Simulation-Based Framework for the Evaluation of Supply Chain Management Policies in the Forest Product Industry". In Proceedings of the the 2012 International Conference on Systems, Man, and Cybernetics, 1742-1748. Seoul, Korea, Republic of: Institute of Electrical and Electronics Engineers, Inc.

Liu, Y., and S. Takakuwa. 2009. "Simulation-Based Personnel Planning for Materials Handling at a Cross-Docking Center Under Retail Distribution Environment". In Proceedings of the 2009 Winter Simulation Conference, edited by R. R. Hill M. D. Rossetti, B. Johansson, A. Dunkin and R. G. Ingalls, 2414-2425. Piscataway, New Jersey: Institute of Electrical and Electronics Engineers, Inc.

Marques, A. F., J. P. de Sousa, M. Rönnqvist, and R. Jafe. 2013. "Combining Optimization and Simulation Tools for Short-Term Planning of Forest Operations." Scandinavian Journal of Forest Research:1-12. 
Santa-Eulalia, L. A., S. D'Amours, and J.-M. Frayret. 2012. "Agent-Based Simulations for Advanced Supply Chain Planning and Scheduling: The FAMASS methodological framework for requirements analysis." International Journal of Computer Integrated Manufacturing 25 (10):963-980.

Sinclair, M., and S. Erasmus. 1992. "A Microcomputer-Based Decision Support System for the Management of Lumber Mill Production." Computers \& Industrial Engineering 22 (4):435-446.

Todoroki, C., and M. Rönnqvist. 1999. "Combined Primary and Secondary Log Breakdown Optimisation." The Journal of the Operational Research Society 50 (3):219-229.

Todoroki, C., and M. Rönnqvist. 2002. "Dynamic Control of Timber Production at a Sawmill with Log Sawing Optimization." Scandinavian Journal of Forest Research 17 (1):79-89.

Wery, J., P. Marier, J. Gaudreault, and A. Thomas. 2014. "Decision-Making Framework for Tactical Planning Taking Into Account Market Opportunities (New Products and New Suppliers) in a Coproduction Context". In Proceedings of the 10th International Conference on Modeling, Optimization and SIMulation, MOSIM'14. Nancy, France.

Wessels, C. B. 2009. "Cant Sawing Log Positioning Optimization: A Simulation Study." Forest Products Journal 59 (4):17-22.

Wessels, C. B., C. Price, P. Turner, and M. Dell. 2006. "Integrating Harvesting and Sawmill Operations Using an Optimized Sawmill Production Planning System.". In Proceedings of the International Precision Forestry Symposium "Precision Forestry in Plantations, Semi-natural and Natural Forests", 341-347. Stellenbosch, South Africa.

\section{AUTHOR BIOGRAPHIES}

JEAN WERY is a Ph.D. student in industrial engineering at Laval University. He holds a Master's degree from the National School of Wood Science and Timber Engineering (ENSTIB) of Lorraine University, France. Previously he had been working for a few years in the industry as a production engineer in Poland. His research interests include simulation and optimization applied to wood processing. $\mathrm{He}$ is currently a student member of FORAC research consortium and CIRRELT (Interuniversity Research Center on Enterprise Networks, Logistics and Transportation). His e-mail address is jean.wery@cirrelt.ca.

PHILIPPE MARIER has been a research professional at FORAC since 2002. He is an Industrial Engineer with an MBA specialized in operations management and decision systems, Philippe has more than 15 years' experience in developing decision aid systems. He contributed to the design and development of many optimization algorithms for the forest products industry. His models are used in solutions for chip replenishment, sawmills strategic investments, transportation planning, sawmills shortterm planning and tactical supply chain design. His e-mail address is Philippe.Marier@forac.ulaval.ca.

JONATHAN GAUDREAULT is co-director of FORAC, a research consortium dedicated to the development of decision support systems for the forest products industry. Over the last twelve years he has led a number of key projects related to operations planning and scheduling, bringing together ideas from the artificial intelligence and operations research fields. He previously worked as an R\&D manager in the software industry and was awarded as "One to watch" (OCTAS award) by the FIQ. In 2012, Dr. Gaudreault and other researchers from the FORAC Research Consortium were recognized with the Brockhouse Canada Prize for Interdisciplinary Research in Science and Engineering, Canada's premier award for interdisciplinary research. His email address is Jonathan.Gaudreault@ift.ulaval.ca.

CORINNE CHABOT is a research and development specialist at the CRIQ (Centre de recherche industrielle du Québec). With over 15 years of experience, she has been working mainly on system design 
related to optimization and production quality management in wood processing. She holds a Bachelor's degree in computer engineering from Laval University. Her email address is Corinne.Chabot@criq.qc.ca.

ANDRE THOMAS is Professor at ENSTIB (High School of Wood Sciences and Timber Engineering) and in charge of a technological research team at CRAN-CNRS - Nancy University. Certified in Value Management and CFPIM, he works with companies producing manufactured goods for research projects. His research topic is hybrid control of supply chains. Hybrid control refers to the use of centralized tactical planning and distributed short-term decision-making systems to control material flow on shop floors and into the supply chains. He is author of several papers published in scientific and technical reviews. He has developed several training tools in industrial engineering in the field of improvement and management of production systems. His email address is Andre.Thomas@univ-lorraine.fr. 